\title{
Design on Framework of Construction Project Management Information System for EPC Contractor
}

\author{
Cui Bo \\ State Key Laboratory of Hydraulic Engineering Simulation and Safety, Tianjin University \\ Tianjin, China 300072 \\ cuib@tju.edu.cn
}

\begin{abstract}
Keywords: EPC; management information system; framework; structure; business model
Abstract. The general framework of management information system for construction projects has been established according to EPC contractor's project management. In the framework which is composed of structure framework and model framework, business models are used to drive system structure, making the system integrated and logical. The framework can be used to promote the application of EPC project management information system.
\end{abstract}

\section{Introduction}

It is necessary to extensively grasp conditions of EPC project management and design professional and widely applicable project management information system framework to promote successful development and application of EPC project management information system. About studies on construction project management information system framework, Stumpf [1] and others establish object-oriented model including project design and construction information. Ma Zhiliang [2] and others propose construction project information management system framework constituted by 4 aspects of management manner of construction project. Halfway [3] and others put forward project management framework based on components, which defines three-layer architecture. The outstanding features of these studies combine information technology and project management mode from the view of project management activities, which has certain reference function to the development of project management information system, but fails to explain the uniform relationship of system structure and business model in details, so the specific guiding function to system development is limited.

Construction project management information system as a kind of management information system, its quality is firstly depended on system structure [4]. The information system structure system understands, analyzes, designs, builds, integrates, expands, operates and manages information system based on business-oriented and driven structure. From the view of application system software development, system structure must be driven by business, and build management software based on business model. The business model determines the success or failure of the overall system [5]. Based on this, the paper considers that, the framework used to direct system development shall be constituted by system structure and business model, and close integration of both of them is the key to successfully develop the system.

\section{General system framework}

The general framework of construction project management information system for EPC contractor is designed as shown in Figure 1. Closely combined with actual project conditions, establish system structure from the views of conceptual structure, hierarchical structure, functional structure and software structure and integrate functional model, organization model, information model and process model to establish business model group, further to form system overall framework constituted by structure framework and model framework. 


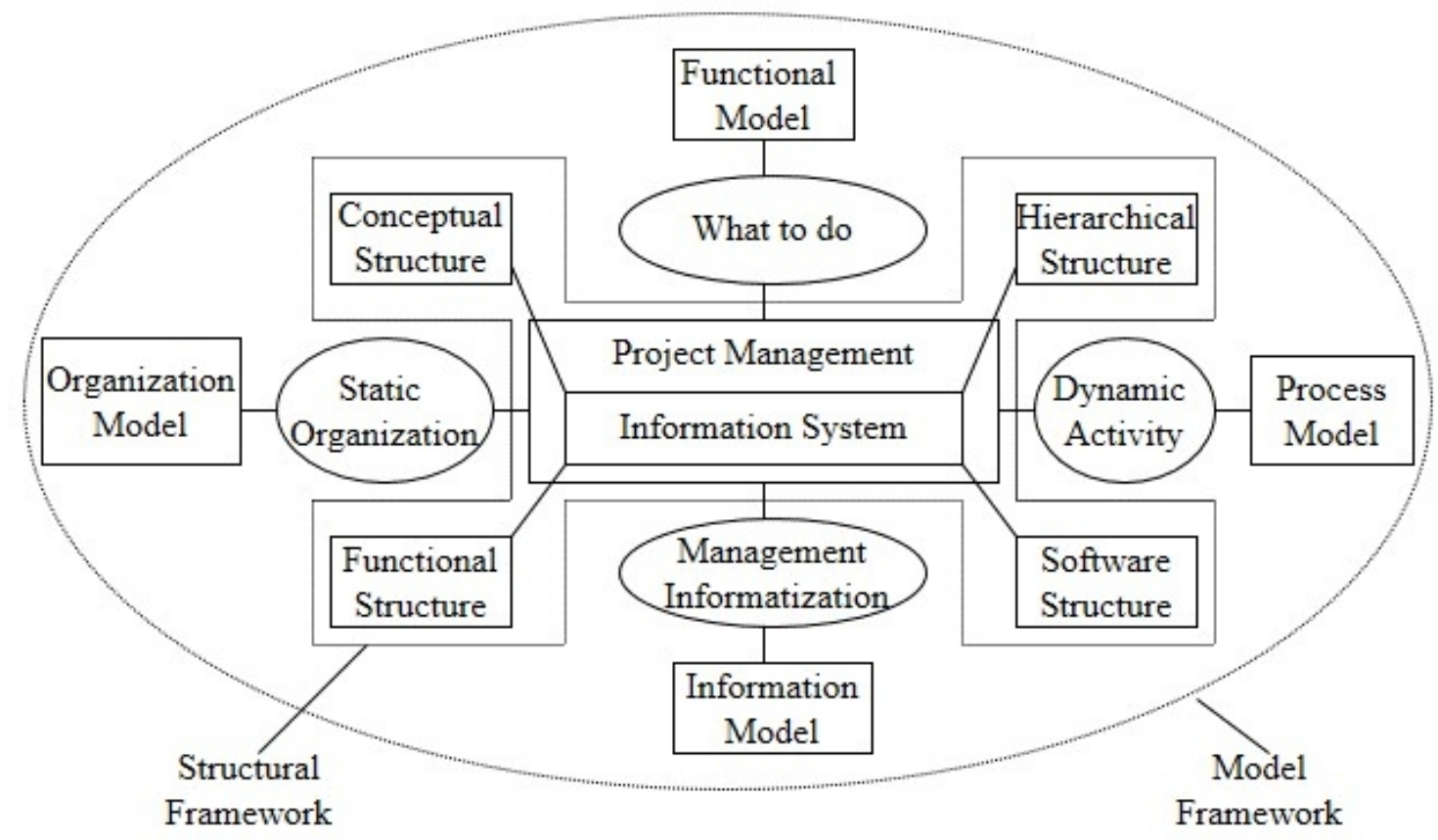

Fig. 1 The general framework of construction project management information system for EPC contractor

\section{Structural framework}

The structure of management information system refers to the framework constituted by components of management information system, and different understanding of different components constitutes different structure manner, mainly including conceptual structure, hierarchical structure, functional structure and software structure, which constitute system structure framework.

(1) Conceptual structure

From the view of concept, management information system consists of four parts: Information source, information processor, and information user and information manager. Information source is the place of origin of information hereunder; Information processor is responsible for delivery, processing and saving of information and other tasks; Information user is the user of information, and applies information to manage and make decision; Information manager is responsible for design and implementation, operation and coordination of information system. Information is transmitted among the four parts.

(2) Hierarchical structure

Management to the project of the general contractor, from the horizontal view, it can be divided into strategic management, management control, operation control and business process according to management hierarchy; From the longitudinal view, it can be divided into progress management, investment management, quality control, etc. according to functions. Generally, amount of information is large processed by under layer while small by upper layer, which forms criss-cross pyramid structure.

(3) Functional structure

Construction project management information system aiming at EPC general contractor shall include the following functions: Engineering progress management, engineering technical management, plan contract management, engineering quality management, equipment management, materials management, safety supervision management, completion final settlement management, integrated query and web portals as well as system maintenance management, in which each functional module may contain multiple sub-modules, and no detailed information here.

(4) Software structure 
Software structure of management information system is the system structure constituted by functional subsystems or modules that support management information system. One software function of management information system may be represented by one function hierarchy matrix, and the row and line of matrix respectively represents function and management hierarchy, cross of row and line representing each functional subsystem. Each functional subsystem has its own specified data document, and there are data and procedure shared by the total system.

(5) Unification of structure framework

The above structures are divided based on different understanding view of management information system, but there are still relations among them. Longitudinal and horizontal integration is conducted based on function/hierarchy matrix, management activities with different hierarchies are integrated in longitudinal view according to the function, and all functions with the same hierarchy are integrated in horizontal view, so that the centralized and unified information, program module sharing and seamless integration of each subsystem function are realized, the software structure formed is the unified embodiment of system structure.

\section{Model framework}

In the design of construction project management information system, the project function, organization, resource, process flow and information flow are described abstractly, namely, the business model group of integrated functional model, organization model, process model and information model is built, and all activities in the execution process shall be managed, supervised, controlled and tracked to provide various useful information for project manager. The business model group constitutes the model framework of system.

(1) Functional model

In EPC project, the project management work of general contractor is involved in the whole process of project implementation phase, the management task includes safety management, investment control and cost control of general contractor, progress control, quality control, contract management, information management and organization and coordination related to general contractor of engineering project. Based on the management task of general contractor, in combination with each functional module in the functional structure of system, the functional model of system can be established.

(2) Organization model

The system organization model is used to describe the standardization of project management organization, which is to show how the organization operates. According to above analysis on EPC management mode, the organization model of system focuses on the management application of general contracting project department, and is combined with the management application of general contractor enterprise; The general contractor is responsible for owners, as well as organization, coordination, control and management for each unit.

(3) Process model

Construction project management process refers to the management activity sequence which generates certain results, in the management process of each phase of construction project life cycle, it can be usually shown as: Start, plan, execute, control and end. System process model is one dynamic model, which describes how the project management activity can be realized under the operation of each organization unit and the support of system resource. The understanding on process is different in different model hierarchies, the process may refer to one business process on the upper layer of model, for example, how the measurement and payment are realized; The process may refer to a specific operation process on the lower layer of model, for example, how to input the quantity of current month.

(4) Information model

The information model is designed by using the information model to store and utilize the functional model, organization model and process model in the manner that the computer can process 
them. Specifically, the information model is used to collect, process, organize and store the information (such as investment control information, quality control information) generated by each participant in the implementation process of project, so that the decision maker can timely and accurately obtain corresponding information by organized information circulation and update. In other words, the information model can complete the contents of functional model under the coordination of organization model according to the process model. These functions of information model support conversion to software system, and to become the design basis of management information system software.

(5) Integrated relation between models

The management process represented by above four models constitutes a complete project management process, and it is recycled in the life cycle of project until the project is completed smoothly.

\section{Combination of structure framework and model framework}

As mentioned above, the software structure is a unified embodiment for structure framework, and the information model is the embodiment of model framework in software form. The information model which can be converted to software system can be used as the drive of software structure without communication barrier, so the structure framework and model framework of system can realize seamless integration by combining their own unified embodiment (software structure and information model).

\section{Conclusions}

The combination of structure framework and model framework of system is realized by information model of system driving software structure to solve two key problems in the management information system development and ensure the completeness and reasonability of management software in the system. Meanwhile, in combination with the structure framework and model framework established by construction project management mode, the project management elements are dissolved in the system framework, so that the system can own a strong applicability.

The paper establishes a general framework of construction project management information system for the project management of EPC general contractor. The framework includes combination of information technology and project management mode as well as information system structure and business model, it has a strong applicability, and it can be used to help the research personnel to design and develop the management information system. The framework is modified on specific content, and also applied to face owner or construction project management information system of other management modes.

\section{Acknowledgements}

This work is financially supported by the National Natural Science Foundation of China (No. 51209159), Tianjin Natural Science Foundation (No. 13JCQNJC08900) and the National Basic Research Program of China (973 Program) (No. 2013CB035906).

\section{References}

[1] Annette L S, Rajaram G, Sangyong C. Journal of Computing in Civil Engineering, 1996, 10 (3)

[2] Ma Zhiliang, Qin Liang, Ren Qiang. China Civil Engineering Journal, 2006, 39 (1)

[3] Mahmoud S, Thomas F. Journal of Computing in Civil Engineering, 2007, 21 (6)

[4] Zhao Naizhen. Design and Application of Information System. Tsinghua University press (2005)

[5] Jiang Xuping, Yao Aiqun. Development of Information System. Tsinghua University press (2004) 